Bulletin of the Seismological Society of America. Vol. 59, No. 2, pp. 923-933. April, 1969

\title{
EXCITATION OF MANTLE LOVE WAVES AND DEFINITION OF MANTLE WAVE MAGNITUDE
}

\author{
By James N. Brune and Gladys R. Engen
}

\begin{abstract}
A study is made of the excitation of mantle Love waves of 100 seconds period as a function of magnitude. 153 measurements of Love wave spectral density for earthquakes since 1930 ranging in magnitude from 6.0 to 8.9 are used to determine an excitation curve. The observations were first corrected to a standard distance of $90^{\circ}$. The excitation curve supports earlier results for mantle Rayleigh waves and, for strike-slip motion, an earlier curve for seismic moment versus mantle-wave magnitude. For dip-slip motion, the moments should be multiplied by a factor of about $2 \frac{1}{2}$. A definition of mantle wave magnitude $M_{M}$, is set up, and the largest earthquake since 1930 found on this scale is the Alaskan earthquake of March 28, 1964 where $M_{M}=$ 8.9. Other comparably large earthquakes, $M_{M}=8.8$, were the Kamchatka earthquake of November 4, 1952 and the Chilean earthquake of May 22, 1960. It is suggested that mantle-wave magnitudes be used as a diagnostic aid in estimating the Tsunami potential of earthquakes.
\end{abstract}

\section{INTRODUCTION}

In a previous paper the excitation of mantle Rayleigh waves of 100 seconds period as a function of magnitude was studied (Brune and King, 1967). We here study the excitation of mantle Love waves of 100 seconds period. It is important to study the excitation of long-period mantle waves because of the information they contain about source mechanism. The amplitudes of waves with period and wavelength long as compared to the time duration and dimensions of the source are directly proportional to the seismic moment of the equivalent double couple which, in turn, is proportional to the product of the rigidity, the area of the dislocation, and the average displacement over the dislocation surface (Maruyama, 1963). Long-period mantle waves are less affected by irregularities in the source mechanism, regional variations in earth structure and scattering and attenuation than shorter-period waves, and thus are simpler to interpret. Theoretical calculations for the excitation of mantle waves are available (Ben-Menahem and Harkrider, 1964).

Brune (1968) has recently used the technique of summing moments to calculate the seismic rate of slip along a given fault zone. He used the results of Brune and King (1967) to determine the shape of a seismic moment versus magnitude curve, and used geodetic and field observations of fault moment as given by Brune and Allen (1967) to set the absolute value of the curve. In this study a curve for the excitation of mantle Love waves as a function of magnitude is obtained from measurements of spectral density of Love waves at a period of 100 seconds. The results of this study support the previous results for excitation of mantle Rayleigh waves and for seismic moment versus magnitude.

Using the excitation curves for mantle Love and Rayleigh waves of 100 seconds period, a definition of mantle-wave magnitude is set up. This magnitude system has several advantages over those based on shorter period waves, but should be thought of as an independent determination of magnitude at a different portion of the spectrum and not an alternate definition of an absolute magnitude. 
DATA

Seismograms used in this study were from a wide variety of instruments. For lower magnitudes, records from the ultra-long period seismographs described by Gilman (1960), and records from the WWNSS were used. For larger earthquakes Milne-Shaw, Wiechert, McComb-Romberg, Wenner, long-period Benioff and Benioff strain meter records were used. Table 1 describes these instruments. Although the magnifications of the older instruments are in some cases uncertain, the uncertainty is not large compared to the expected range of amplitudes and is probably not systematic. Amplitude spectral densities of mantle Love waves at a period of 100 seconds are the basic

TABLE 1

INSTRUMENTS

\begin{tabular}{llc}
\hline \multicolumn{1}{c}{ Stations } & \multicolumn{1}{c}{ Instrument } & Ampl. at 100 Sec \\
\hline PAS & Gilman ULP NS & 590 \\
PAS & Gilman ULP EW & 480 \\
PAS & Gilman ULP EW & 1960 \\
PAS & Gilman ULP EW & 290 \\
ALQ, ANT, BOZ, CMC, NNA & WWNSS & 430 \\
COP, LAH, NOR, STU & WWNSS & 108 \\
DUG, MNN & WWNSS & 1200 \\
HNR & WWNSS & 290 \\
MAT, QUE, TRI & WWNSS & 890 \\
ATU, COL, MSH, NDI, NUR, RCD, SHI & WWNSS & 210 \\
OTT, SFA, TNT, VIC & Milne-Shaw & 4 \\
SJP & Wenner & 9.4 \\
BOZ, SLC & McComb-Romberg & 3.2 \\
CHI & McComb-Romberg & 3.35 \\
COL & McComb-Romberg & 2.0 \\
CSC, UKI & McComb-Romberg & 1.07 \\
TUC & Wood-Anderson & 2.76 \\
JEN, BER & Wiechert & $1.5^{*}$ \\
PAS & Strain & $4.4^{*}$ \\
PAS & Strain & $4.0^{*}$ \\
KIP & Strain & $28^{*}$ \\
PAS & L. P. Benioff & $25^{*}$ \\
\hline
\end{tabular}

* From Brune \& King (1967).

data for this study. Spectral densities were determined by Fourier analysis both graphically and with the aid of a 7090 computer. Amplitude spectral densities rather than simple amplitudes were used since mantle Love waves are not sufficiently dispersed for the stationary phase approximation to be valid, i.e., the wave is pulse-like. This pulse-like wave has been named the $G$ wave after Gutenberg by Byerly (1926). Typical $G$ waves used in this study are shown in Figure 1. The amplitude spectral densities are corrected to a standard distance of $90^{\circ}$. The correction curve is given in Figure 2. This curve corresponds to the function $\left(\sin \Delta^{\circ}\right)^{1 / 2} \cdot e^{\pi(x-10000) / Q U T}$ where $\Delta$ is the distance in degrees, $x$ is the distance in kilometers, $U$ is the group velocity, $T$ is the period, and $Q$ is the seismic quality factor. $Q$ is taken to have a value of 107 at $T=$ 100 sec as found by Ben-Menahem (1965). The validity of the correction has been checked by numerous comparisons of reduced spectral densities from G1 and G3, G2 and G4, and G3 and G5 waves. Amplitude spectral densities determined for 153 recordings of mantle Love waves (corrected to a distance $90^{\circ}$ ) are given in Table 2, and the corresponding amplitude spectral densities averaged for each earthquake are 
plotted as a function of magnitude in Figure 3. For earthquakes earlier than 1956 the magnitude values cited are those given in Richter (1958) when $M>7.9$ and those given in Gutenberg and Richter (1954) when $M<7.9$. For earthquakes after 1956 the magnitude cited is the magnitude assigned by Pasadena.
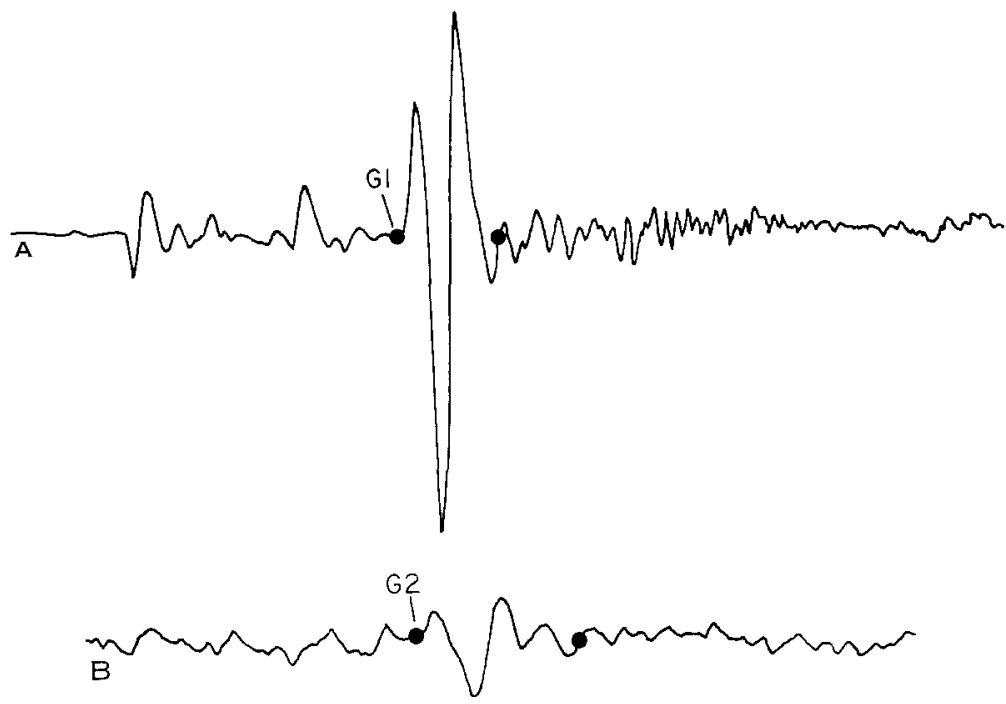

Fra. 1. Seismograms illustrating ty pical mantle Love waves used in this study. The seismogram illustrating G1 is for the Easter Island shock of 7 March $1963\left(M=6 \frac{3}{4}\right)$; G2 is for the Kermadec Islands shock of 20 May $1963\left(M=66_{4}^{3}-7\right)$. Both were recorded on a CIT ULP instrument at Pasadena (Gilman, 1960).

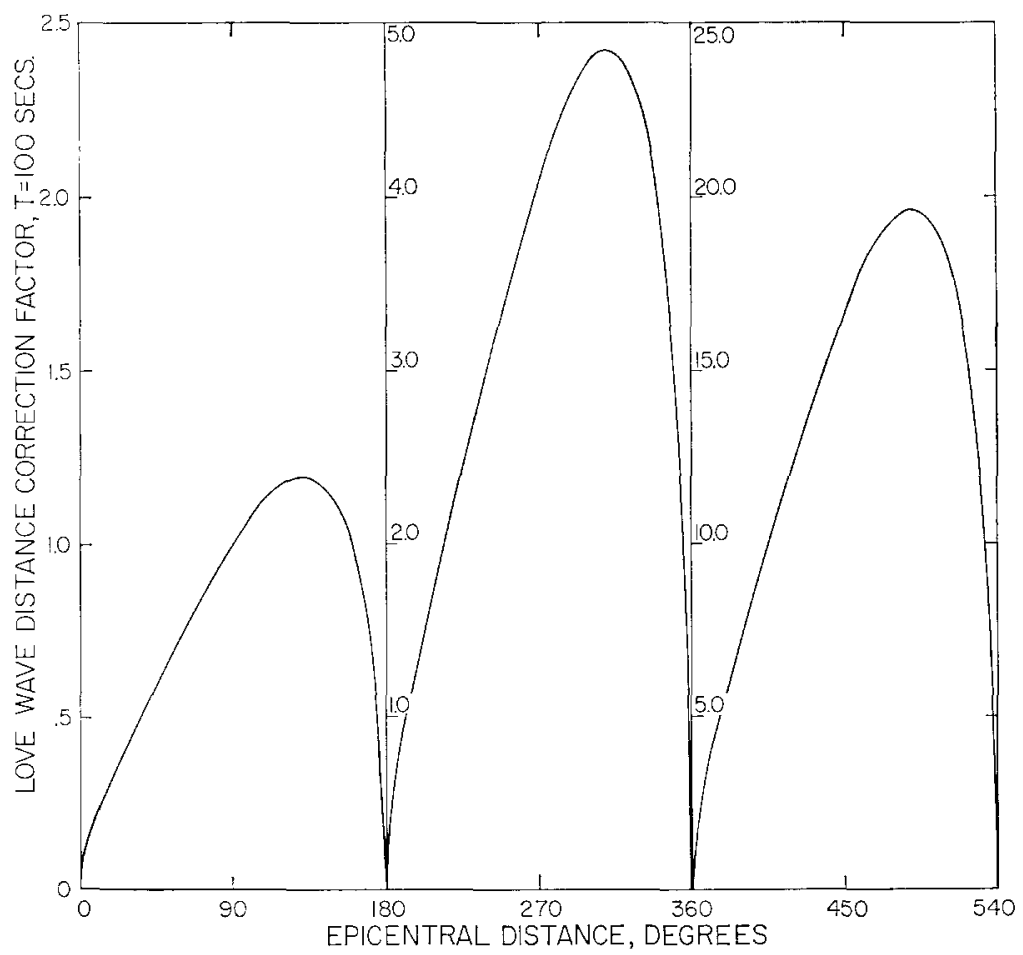

FIG. 2. Spectral density distance correction factor for 100 second period mantle Love waves. The correction curve may be extended to larger distances using the equation given in the text. 
TABLE 2

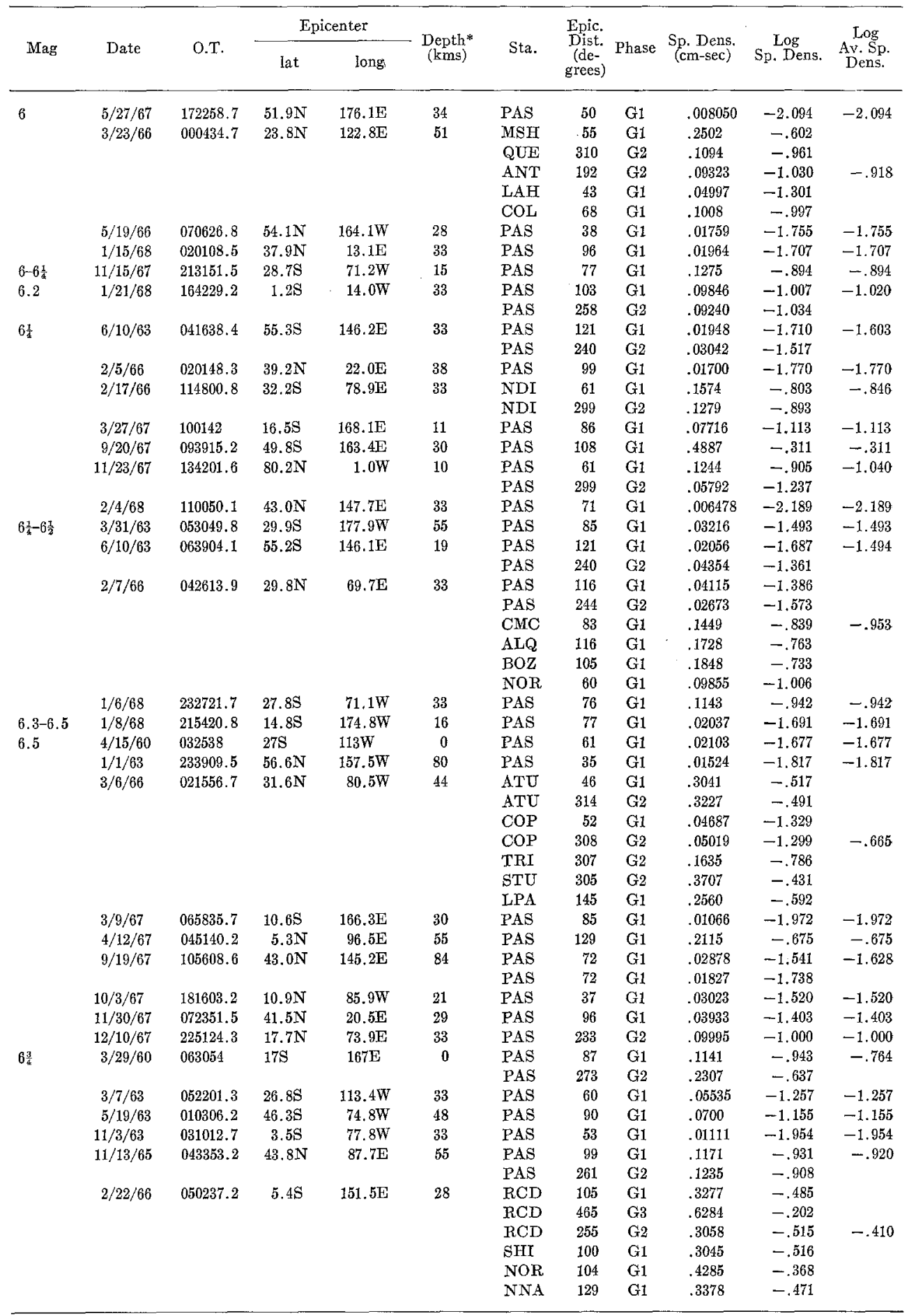


TABLE 2-Continued

\begin{tabular}{|c|c|c|c|c|c|c|c|c|c|c|c|}
\hline \multirow{2}{*}{ Mag } & \multirow{2}{*}{ Date } & \multirow{2}{*}{ O.T. } & \multicolumn{2}{|c|}{ Epicenter } & \multirow{2}{*}{$\begin{array}{c}\text { Depth* } \\
\text { (kms) }\end{array}$} & \multirow{2}{*}{ Sta. } & \multirow{2}{*}{$\begin{array}{c}\text { Fpic. } \\
\text { Dist. } \\
\text { (de- } \\
\text { glees) }\end{array}$} & \multirow{2}{*}{ Phase } & \multirow{2}{*}{$\begin{array}{l}\text { Sp. Dens. } \\
(\mathrm{cm} \mathrm{sec})\end{array}$} & \multirow{2}{*}{$\begin{array}{l}\text { Log } \\
\text { Sp. Dens. }\end{array}$} & \multirow{2}{*}{$\begin{array}{l}\text { Log } \\
\text { Av. Sp. } \\
\text { Dens. }\end{array}$} \\
\hline & & & lat & long & & & & & & & \\
\hline & $5 / 21 / 67$ & 184511.7 & $1.0 \mathrm{~S}$ & $101.5 \mathrm{E}$ & 173 & PAS & 131 & G1 & .02720 & -1.565 & -1.565 \\
\hline & $10 / 4 / 67$ & 172120.7 & $5.7 \mathrm{~S}$ & $153.9 \mathrm{E}$ & 52 & PAS & 92 & $\mathrm{G} 1$ & .3010 & -.521 & -.521 \\
\hline & $10 / 18 / 67$ & 011145 & $79.8 \mathrm{~N}$ & $2.4 \mathrm{E}$ & 33 & PAS & 62 & G1 & .2269 & -.644 & -.644 \\
\hline & & & & & & PAS & 267 & $\mathrm{G} 2$ & .1649 & -.783 & \\
\hline \multirow[t]{8}{*}{$6 \frac{\pi}{4}-7$} & $3 / 26 / 63$ & 094820.3 & $29.7 \mathrm{~S}$ & $177.9 \mathrm{~W}$ & 48 & PAS & 85 & $\mathrm{G} 1$ & .4321 & -.384 & -.370 \\
\hline & & & & & & PAS & 275 & $\mathrm{G} 2$ & .4208 & -.376 & \\
\hline & $5 / 20 / 63$ & 113805.3 & $30.7 \mathrm{~S}$ & $178.3 \mathrm{~W}$ & 68 & PAS & 275 & $\mathrm{G} 2$ & .1041 & -.983 & -.983 \\
\hline & $10 / 20 / 63$ & 005307.2 & $44.7 \mathrm{~N}$ & $150.7 \mathrm{E}$ & 25 & PAS & 292 & $\mathrm{G} 2$ & 1.679 & .225 & .225 \\
\hline & $5 / 20 / 65$ & 004010.9 & $14.7 \mathrm{~S}$ & $167.4 \mathrm{E}$ & 59 & PAS & 86 & $\mathrm{G} 1$ & .2036 & -.691 & -.831 \\
\hline & & & & & & PAS & 274 & G2 & .09180 & -1.037 & \\
\hline & $3 / 20 / 66$ & 014249.9 & $0.6 \mathrm{~N}$ & $30.2 \mathrm{E}$ & 36 & PAS & 135 & G1 & .1059 & -.975 & -.975 \\
\hline & $3 / 4 / 67$ & 175806.4 & $39.2 \mathrm{~N}$ & $24.6 \mathrm{E}$ & 33 & PAS & 99 & G1 & .1965 & -.707 & -.707 \\
\hline \multirow[t]{8}{*}{7} & $6 / 20 / 60$ & 020108 & $38 \mathrm{~S}$ & $73 \frac{1}{2} W^{\prime}$ & 0 & PAS & 277 & G2 & .6050 & -.218 & -.218 \\
\hline & $11 / 24 / 60$ & 065241.1 & $24.2 \mathrm{~S}$ & $176.1 \mathrm{~W}$ & 23 & PAS & 280 & G2 & .9070 & -.045 & -.045 \\
\hline & $3 / 16 / 63$ & 084451.1 & $46.6 \mathrm{~N}$ & $154.8 \mathrm{E}$ & 46 & PAS & 296 & $\mathrm{G} 2$ & 1.262 & .101 & .020 \\
\hline & & & & & & PAS & 65 & G1 & .8321 & -.080 & \\
\hline & $4 / 19 / 63$ & 073522.7 & $35.7 \mathrm{~N}$ & $96.9 \mathbf{E}$ & 33 & PAS & 464 & G3 & 1.028 & .012 & -.180 \\
\hline & & & & & & PAS & 256 & G2 & .2942 & -.532 & \\
\hline & $12 / 21 / 67$ & 022521.6 & $21.8 \mathrm{~S}$ & $70.0 \mathrm{~W}$ & 33 & PAS & 288 & G2 & 2.945 & .469 & .469 \\
\hline & $8 / 19 / 66$ & 122209.6 & $39.2 \mathrm{~N}$ & $41.7 \mathrm{E}$ & 26 & PAS & 105 & G1 & .03645 & -1.438 & -1.438 \\
\hline $7-7 \frac{1}{8}$ & $8 / 2 / 65$ & 131955.9 & $56.2 \mathrm{~S}$ & $158.2 \mathrm{E}$ & 33 & PAS & 115 & G1 & .1667 & -.778 & \\
\hline & & & & & & HNR & 313 & G2 & 3.757 & .575 & .220 \\
\hline & & & & & & MAT & 454 & G3 & 2.384 & .377 & \\
\hline & & & & & & NUR & 156 & G1 & .3330 & -.482 & \\
\hline & $2 / 12 / 68$ & 054447.6 & $5.5 \mathrm{~S}$ & $153.2 \mathrm{E}$ & 74 & PAS & 268 & $\mathrm{G}_{2}$ & 1.723 & .236 & .236 \\
\hline $7 \frac{1}{4}$ & $5 / 21 / 60$ & 100250 & $37 \frac{1}{2} \mathrm{~S}$ & $73 \frac{1}{2} W$ & 0 & CHI & 80 & G1 & 4.612 & .664 & .664 \\
\hline $7 \frac{1}{4}-7 \frac{1}{2}$ & $5 / 22 / 60$ & 103243 & $37 \frac{1}{3} \mathrm{~S}$ & $73 \mathrm{~W}$ & 0 & SLC & 86 & G1 & .1415 & -.849 & -.849 \\
\hline & $11 / 1 / 60$ & 084601.9 & $38.4 \mathrm{~S}$ & $74.4 \mathrm{~W}$ & 97 & PAS & 83 & G1 & .3252 & -.488 & -.392 \\
\hline & & & & & & PAS & 277 & $\mathrm{G}_{2}$ & .4854 & -.314 & \\
\hline & $9 / 15 / 63$ & 004654.1 & $10.3 \mathrm{~S}$ & $165.6 \mathrm{E}$ & 43 & PAS & 85 & G1 & .4985 & -.302 & -.302 \\
\hline 7.4 & $4 / 1 / 46$ & 122854 & $52 \frac{3}{4} \mathrm{~N}$ & $163 \frac{1}{2} \mathrm{~W}$ & & $\mathrm{BOZ}$ & 34 & $\mathrm{G} 1$ & 8.412 & .925 & \\
\hline & & & & & & $\mathrm{BOZ}$ & 326 & G2 & 4.646 & .667 & \\
\hline & & & & & & CHI & 50 & G1 & 3.897 & .591 & \\
\hline & & & & & & $\mathrm{CHI}$ & 310 & $\mathrm{G} 2$ & 3.799 & .580 & \\
\hline & & & & & & $\mathrm{COL}$ & 346 & G2 & 5.006 & .699 & \\
\hline & & & & & & $\mathrm{COL}$ & 374 & G3 & 7.637 & .883 & .844 \\
\hline$\therefore$ & & & & & & CSC & 59 & G1 & 8.511 & .930 & \\
\hline . & & & & & & SLC & 36 & G1 & 4.421 & .646 & \\
\hline & & & & & & UKI & 31 & $\mathrm{G} 1$ & 5.241 & .719 & \\
\hline & & & & & & WES & 418 & G3 & 9.997 & $1.00 n$ & \\
\hline & & & & & & TUC & 43 & G1 & 15.18 & 1.181 & \\
\hline 7.5 & $9 / 12 / 61$ & 220658.5 & $49.05 \mathrm{~S}$ & $164.26 \mathrm{E}$ & 33 & DUG & 475 & G3 & 1.063 & .027 & \\
\hline & & 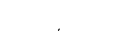 & & & & DUG & 605 & G4 & .5340 & -.272 & -.099 \\
\hline & & & & & & MNN & 489 & G3 & .7911 & -.102 & \\
\hline 7.7 & $7 / 18 / 34$ & 013624 & $8 \mathrm{~N}$ & $82 \frac{1}{2} W$ & & VIC & 53 & G1 & 2.959 & .471 & .471 \\
\hline 7.9 & $6 / 17 / 28$ & 031927 & $16_{4}^{1} \mathrm{~N}$ & $98 \mathrm{~W}$ & & $\mathrm{VIC}$ & 321 & G2 & 12.04 & 1.081 & 1.081 \\
\hline & $8 / 10 / 31$ & 211840 & $47 \mathrm{~N}$ & $90 \mathrm{E}$ & & SFA & 277 & G2 & 31.49 & 1.498 & 1.498 \\
\hline 8.1 & $6 / 3 / 32$ & 103650 & $19.5 \mathrm{~N}$ & $104.25 \mathrm{~W}$ & & VIC & 327 & $\mathrm{G} 2$ & 16.43 & 1.216 & 1.216 \\
\hline & $7 / 18 / 34$ & 194015 & $11 \frac{3}{4} \mathrm{~S}$ & $166 \frac{1}{2} \mathrm{E}$ & & TNT & 245 & $\mathrm{G} 2$ & 5.447 & .736 & .736 \\
\hline $8 \frac{1}{4}-8 \frac{1}{2}$ & $5 / 22 / 60$ & 191120 & $38 \mathrm{~S}$ & $73 \frac{1}{2} W$ & 0 & SLC & 274 & G2 & 69.54 & 1.842 & 1.861 \\
\hline & & & & & & $\mathrm{CHI}$ & 280 & $\mathrm{G} 2$ & 75.67 & 1.879 & \\
\hline 8.3 & $9 / 1 / 23$ & 025836 & $35 \frac{1}{4} \mathrm{~N}$ & $139 \frac{1}{2} \mathrm{E}$ & & OTT & 266 & G2 & 20.62 & 1.314 & 1.314 \\
\hline & $12 / 1 / 28$ & 040610 & $35 \mathrm{~S}$ & $72 \mathrm{~W}$ & & VIC & 265 & G2 & 4.857 & .686 & .686 \\
\hline & $5 / 14 / 32$ & 131100 & $.5 \mathrm{~N}$ & 126.E & & TNT & 230 & G2 & 5.722 & .758 & \\
\hline & & & & & & VIC & 257 & $\mathrm{G}_{2}$ & 5.877 & .769 & 1.017 \\
\hline & & & & & & SFA & 231 & $\mathrm{G} 2$ & 19.62 & 1.292 & \\
\hline & $8 / 6 / 42$ & 233659 & $14 N$ & $91 \mathrm{~W}$ & $50-60$ & $\mathrm{COL}$ & 64 & $\mathrm{G} 1$ & 2.133 & .329 & .383 \\
\hline & & & & & & $\mathrm{CHI}$ & 332 & $\mathrm{G} 2$ & 2.694 & .430 & \\
\hline
\end{tabular}


TABLE 2-Continued

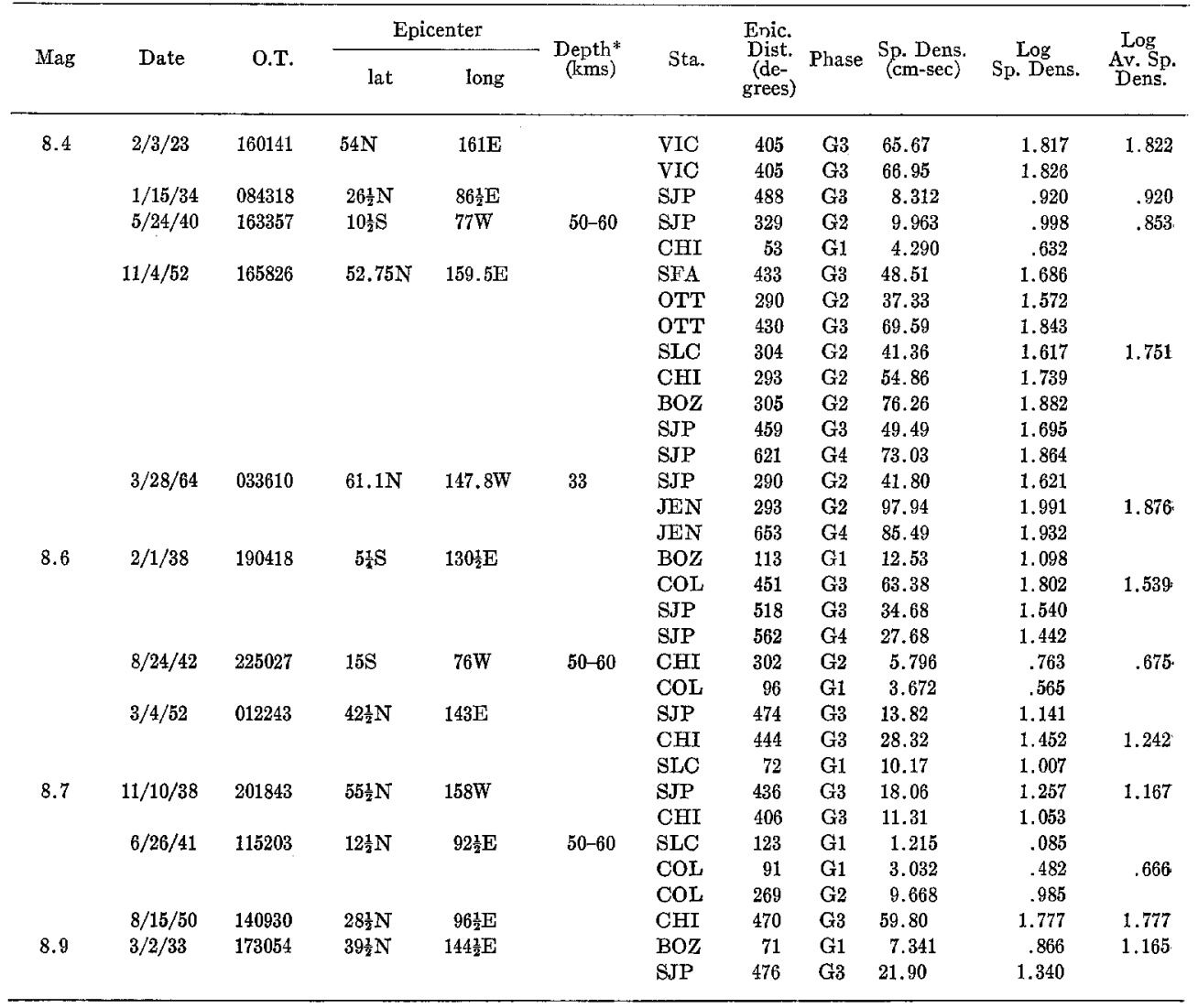

* Unless otherwise noted, depth is normal.

The data cover a magnitude range from 6.0 to 8.9 and a range of spectral densities from $.0065 \mathrm{~cm}$-sec to $97.94 \mathrm{~cm}$-sec. The data are in good agreement with a curve having the shape of the $X_{20} / X_{100}$ curve given by Brune and King for mantle Rayleigh waves. The deflection of this curve between magnitudes 7 and 7.1 is due to the interference effects of a propagating rupture. The curve has been fitted to the data by adjusting its level so that an equal number of observations fall above and below the curve. The scatter of the data from a single line is about one magnitude unit, i.e., a factor of 10 . This is about the same scatter as observed for mantle Rayleigh waves.

\section{SEIsmic MOMENT}

A curve for seismic moment versus magnitude was derived from the shape of the 100 second mantle Rayleigh wave amplitude versus magnitude curve by Brune (1968). Using the theoretical curves of Ben-Menahem and Harkrider (1964) we also can set the moment versus magnitude scale for our data by finding the moment corresponding to spectral density of a given magnitude, e.g., $M=6$. The spectral density for $M=6$ taken from the curve in Figure 3 is $.0229 \mathrm{~cm}$-sec. For a pure strike-slip fault at a depth of $10 \mathrm{~km}$ observed at an average azimuth this corresponds to a seismic moment of $1.59 \times 10^{25}$ dyne-cm. For a pure dip-slip motion on a fault dipping $60^{\circ}$ this corresponds to a seismic moment of $3.89 \times 10^{25} \mathrm{dyne-cm}$. An average for 100 cases of fault orientation and depth was found to be $3.09 \times 10^{25}$ dyne-cm. In these cases dip was varied 
from $10^{\circ}$ to $90^{\circ}$, motion was varied from pure dip-slip to pure strike-slip and depth was varied from $10 \mathrm{~km}$ to $60 \mathrm{~km}$. A value of $Q$ equal to 107 was assumed, and a correction of 0.8 was used for sphericity.

On the basis of the above calculations we estimate that the mantle Love wave amplitude spectral density for $M=6, .0229 \mathrm{~cm}$-sec., corresponds to a source moment of $1.66 \times 10^{25}$ dyne-cm* for the case of pure strike-slip motion. This value is not signifcantly different from the value taken from the curve for moment versus magnitude obtained by Brune using observations of field displacement during faulting, and

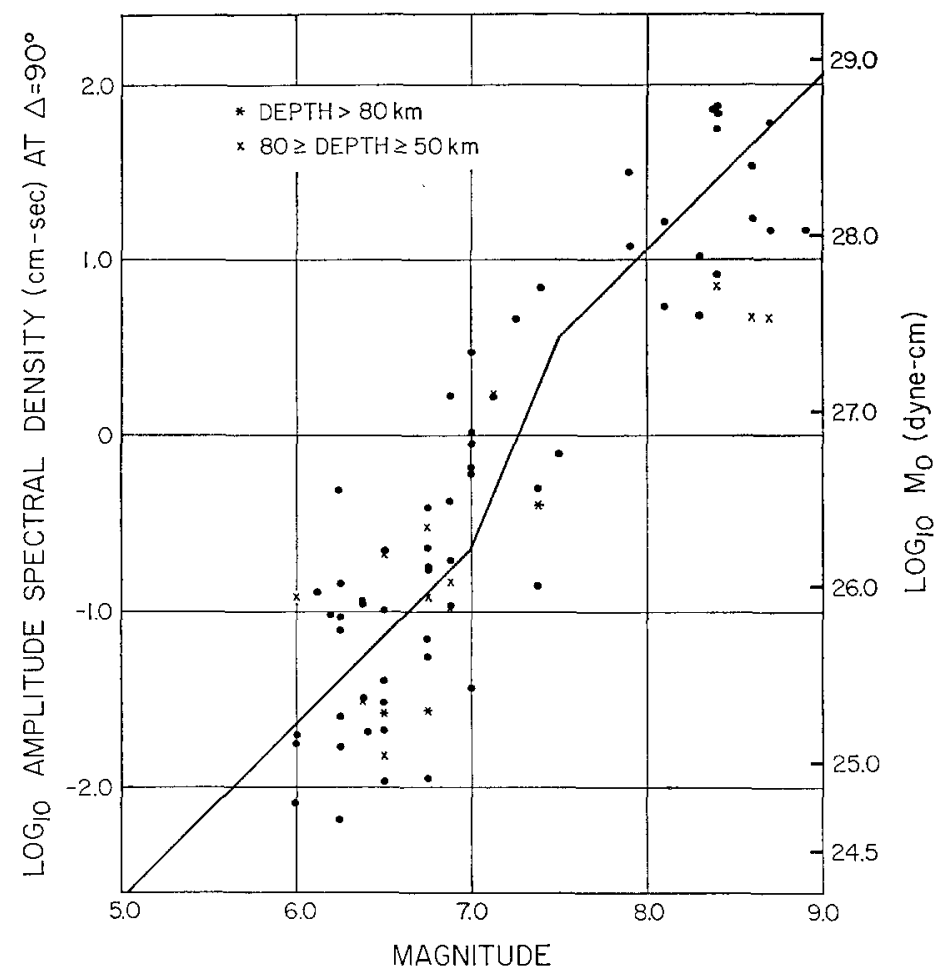

Fra. 3. Logarithm to the base 10 of mantle Love wave spectral densities averaged for each earthquake at a distance of $90^{\circ}$, plotted as a function of magnitude, $M$. The curve fitted to the points has the shape of the $X_{20} / X_{100}$ curve of Brune and King (1967) for mantle Rayleigh waves and is used in the definition of mantle wave magnitude.

therefore the same scale on the right hand margin of Figure 3 is retained for strike-slip motion. For dip-slip motion, the moment obtained from this scale should be multiplied by a factor of about $2 \frac{1}{2}$. When possible, the mantle wave magnitude, described below, rather than the 20 second surface-wave magnitude, should be used to estimate source moment.

\section{Definition of Mantle Wave Magnitude}

Having curves for the excitation of both mantle Love waves and mantle Rayleigh waves as a function of magnitude, it is possible to define mantle wave magnitude $M_{M}$, by these curves. Mantle wave magnitude is determined independently using 100 second period Love waves and 100 second period Rayleigh waves, and the two values are averaged by averaging their antilogs. When data for more than one station are available, all values obtained are averaged $\left(M_{M}=\log\right.$ [average of antilogs of indi-

* Average for depths varying from $10-60 \mathrm{~km}$. 
vidual $M_{M}$ 's]). This averaging will tend to remove scatter in the determination of magnitude, since it is unlikely that a given station will be at a node in the radiation pattern for both Love waves and Rayleigh waves. An example of such a calculation is given in Table 3. The curves defining magnitude are given in Figure 3 for Love waves

TABLE 3

Example of Averaging Values

\begin{tabular}{|c|c|c|c|c|c|c|}
\hline Date & Earthquake & Sta. & $\underset{\text { Mag }}{\text { Mantle Love }}$ & $\begin{array}{c}\text { Mantle Rayleigh } \\
\text { Mag }\end{array}$ & Station Mag & $\begin{array}{c}\text { Mantle Wave } \\
\text { Mag }\end{array}$ \\
\hline \multirow[t]{3}{*}{$3 / 4 / 52$} & Japan & SJP & 8.1 & 7.5 & 7.9 & \\
\hline & & $\mathrm{CHI}$ & 8.4 & $\begin{array}{l}8.4 \\
8.5\end{array}$ & 8.4 & \\
\hline & & SLC & 8.0 & 8.4 & 8.2 & 8.3 \\
\hline
\end{tabular}

Mag $=\log$ (average of antilog of Love and Rayleigh mags).

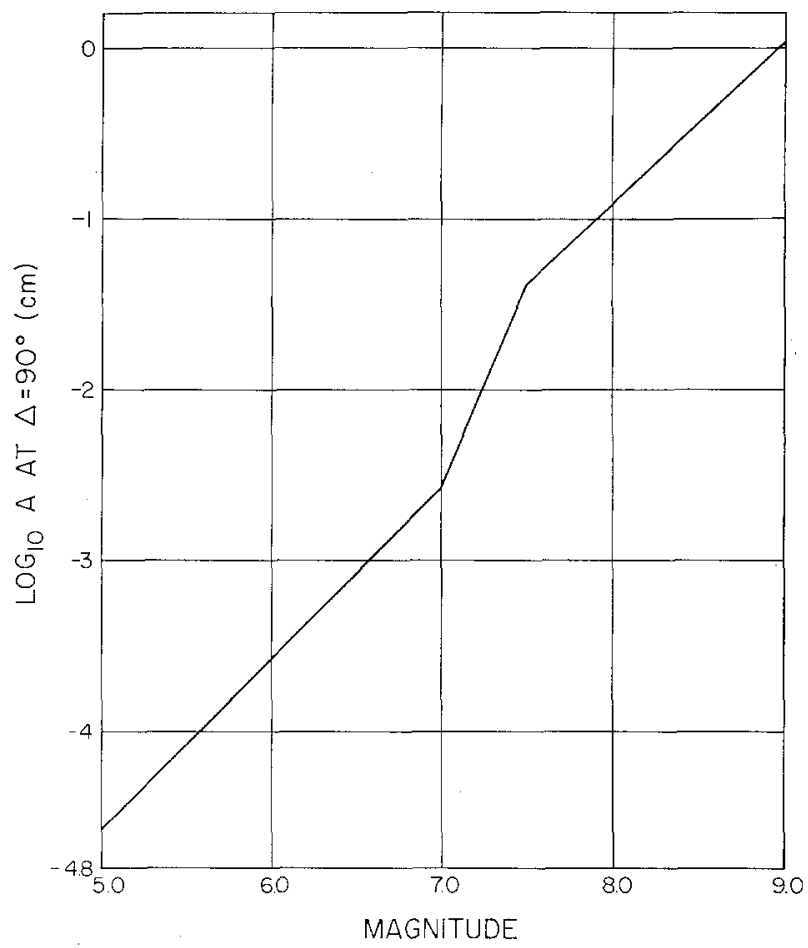

FIG. 4. Logarithm to the base 10 of the amplitude of vertical ground motion (in cms.) of 100 second period mantle Rayleigh waves at a distance of $90^{\circ}$, plotted as a function of magnitude $M$ (Brune and King, 1967). This curve is used in the definition of mantle wave magnitude.

and in Figure 4 for Rayleigh waves. The distance correction curve for Rayleigh waves is given in Figure 5 (combining the two correction curves given by Brune and King, 1967). Note that for Rayleigh waves, ground amplitude is used, and for Love waves ground spectral density is used. Ground amplitude may be approximately converted to spectral density for the Love waves by multiplying by 70 seconds. This approximation will be best if the G-wave pulse has a predominant period of about 100 seconds and will not be valid if the predominant period varies greatly from this; Fourier analysis should be used. The approximation has not been used in this study but can 
be used for preliminary assignment of mantle-wave magnitude. The instruments described by Gilman (1960) are ideal for using this definition of magnitude, since their peak response is near 100 seconds.

A 3-component, long-period, low magnification seismograph systiem specially designed to record mantle waves has recently been installed at Cal-Tech. The system uses 35-second pendulums with electromagnetic transducers, coupled to 100 -second galvanometers through a 2-stage low-pass filter. This arrangement yields a periodmagnification response peaking at 100 seconds with maximum magnification of 25 . Low sensitivity is used with the hope of obtaining on scale recordings of low order

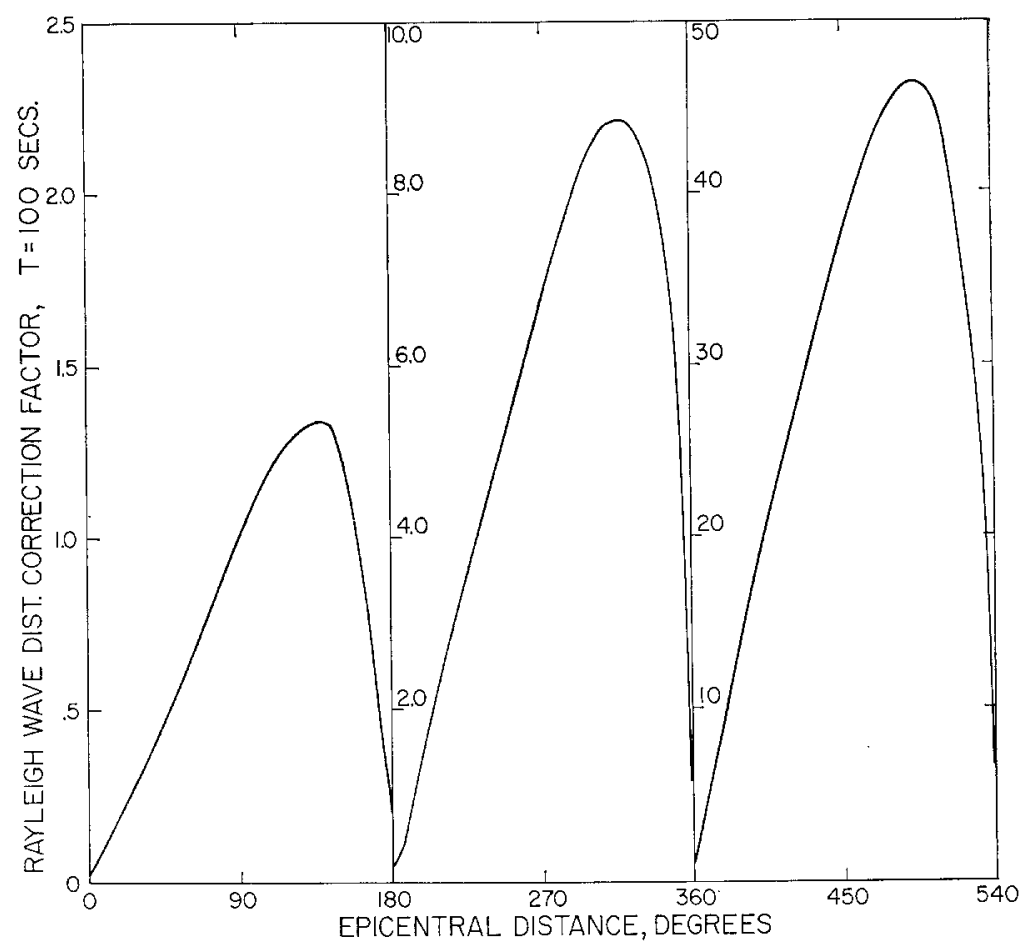

FIG. 5. Amplitude distance correction factor for 100 second period mantle Rayleigh waves (combining factors $A$ and $B$ of Brune and King, 1967).

mantle waves from the largest teleseisms. However, even with the low sensitivity mantle waves are clearly recorded from shocks as small as $M=6.0$.

Using the mantle wave magnitude scale, we have determined mantle wave magnitudes $M_{M}$ for several of the largest earthquakes since 1930, and these results are presented in Table 4. The largest earthquake of those examined since 1930 based on this scale is the Alaskan earthquake of March 28, $1964\left(M_{M}=8.9\right)$; other earthquakes of comparably large size $\left(M_{M}=8.8\right)$ are the Kamchatka earthquake of November 4 , 1952 and the Chilean earthquake of May 22, 1960. Surprisingly the Sanriku, Japan, earthquake of March 2, 1933 which is given a magnitude of 8.9 by Gutenberg (1956) has a mantle wave magnitude of only 8.4. Thus the very long-period excitation by this earthquake was relatively small.

\section{Mantre Waves as a Diagnostic Aid for the Tsunami Warning System}

Since Seismic Sea waves are very long period it might be expected that the mantle wave magnitude of an earthquake would be a more suitable diagnostic aid for Tsunami 
warnings than the ordinary 20 second surface wave magnitude. The critical earthquake for testing this idea is the April 1st, 1946 Aleutian earthquake which caused a destructive Tsunami even though the surface wave magnitude was only 7.4. The mantle wave magnitude for this event, determined by averaging 11 phases at 8 stations is 7.8 . Thus the long-period excitation was relatively great and using the mantle wave magnitude we would have considered this earthquake more likely to generate a Tsunami than we would have using the 20 second surface wave magnitude. This suggests that whenever possible the mantle wave magnitude should be used as a diagnostic aid in estimating the Tsunami potential of an earthquake.

TABLE 4

Mantle Wave Magnitudes

\begin{tabular}{rcllcrr}
\hline No. & Date & Location of Earthquake & Pas Mag & $\begin{array}{c}\text { Mantle Wave } \\
\text { Mag }\end{array}$ & $\begin{array}{c}\text { *of } \\
\text { Stations } \\
\text { Read }\end{array}$ & $\begin{array}{c}\text { * of Phases } \\
\text { Averaged }\end{array}$ \\
\hline 1 & $3 / 28 / 64$ & Alaska & 8.4 & 8.9 & 4 & 8 \\
2 & $11 / 4 / 52$ & Kamchatka & 8.4 & 8.8 & 7 & 17 \\
3 & $5 / 22 / 60$ & Chile & $8 \frac{1}{1}-8 \frac{1}{2}$ & 8.8 & 3 & 5 \\
4 & $8 / 15 / 50$ & Assam & 8.7 & 8.7 & 2 & 3 \\
5 & $2 / 3 / 23$ & Kamchatka & 8.4 & $8.7 \dagger$ & 1 & 4 \\
6 & $8 / 10 / 31$ & Mongolia & 7.9 & $8.6 \dagger$ & 1 & 2 \\
7 & $2 / 1 / 38$ & New Guinea & 8.6 & 8.5 & 3 & 7 \\
8 & $6 / 17 / 28$ & Mexico & 7.9 & $8.4 \dagger$ & 1 & 3 \\
9 & $3 / 2 / 33$ & Sanriku & 8.9 & 8.4 & 4 & 6 \\
10 & $11 / 10 / 38$ & Alaska Peninsula & 8.7 & 8.3 & 2 & 4 \\
11 & $3 / 4 / 52$ & Japan & 8.6 & 8.3 & 3 & 7 \\
12 & $6 / 3 / 32$ & Mexico & 8.1 & 8.2 & 2 & 4 \\
13 & $9 / 1 / 23$ & Tokyo & 8.3 & $8.2 \dagger$ & 1 & 2 \\
14 & $5 / 24 / 40$ & Peru & 8.4 & $8.1^{*}$ & 2 & 3 \\
15 & $1 / 15 / 34$ & India & 8.4 & 8.0 & 2 & 3 \\
16 & $6 / 26 / 41$ & Andaman Isls. & 8.7 & $8.0^{*}$ & 2 & 5 \\
17 & $5 / 14 / 32$ & Halmahera Isls. & 8.3 & 7.9 & 3 & 7 \\
18 & $12 / 1 / 28$ & Chile & 8.3 & $7.9 \dagger$ & 1 & 2 \\
19 & $8 / 24 / 42$ & Peru & 8.6 & $7.9^{*}$ & 2 & 5 \\
20 & $8 / 6 / 42$ & Guatemala & 8.3 & $7.9^{*}$ & 2 & 4 \\
21 & $7 / 18 / 34$ & Santa Cruz Isls. & 8.1 & $7.8 \dagger$ & 1 & 3 \\
\hline
\end{tabular}

$* H=50-60 \mathrm{~km}$.

$\dagger$ Magnitude based on one station may not be representative.

\section{Conclusions}

(1) A curve for the excitation of 100-second period mantle Love waves as a function of Pasadena magnitude has been obtained from 153 measurements of spectral density of mantle Love waves.

(2) The curve for excitation of mantle Love waves as a function of magnitude agrees with the curve for excitation of mantle Rayleigh waves of 100 -second period obtained by Brune and King (1967), and, in the case of strike-slip motion, agrees with the curve for seismic moment versus magnitude obtained by Brune (1968). For dip-slip motion, the curve for seismic moment should be multiplied by a factor of about $2 \frac{1}{2}$.

(3) A definition of mantle-wave magnitude has been set up, and the largest earthquake since 1930 found on this scale is the Alaskan earthquake of March 28, 1964; $M_{M}=8.9$. Other comparably large earthquakes, $M_{M}=8.8$, were the Kamchatka. earthquake of November 4, 1952 and the Chilean earthquake of May 22, 1960. 
(4) It is suggested that mantle wave magnitude be used as a diagnostic aid in estimating the Tsunami potential of an earthquake. The Aleutian earthquake of April 1, 1946 is given as an example of an earthquake which generated a destructive Tsunami and for which the mantle wave magnitude (7.8) would have been more indicative of Tsunami potential than the surface wave magnitude (7.4).

\section{ACKNOWLEDGMENTS}

The authors are indebted to Professor Charles F. Richter for critically reading the manuscript and offering constructive criticism. Thanks are due Mr. Ralph Gilman who provided records and calibration curves from the Pasadena (PAS) ULP instruments, and to the U. S. Coast and Geodetic Survey for supplying records. This research was supported by the National Science Foundation under Grant GA 1087 (Earthquake Mechanism).

\section{REFERENCES}

Ben-Menahem, A. (1965). Observed attenuation and $Q$ values of seismic surface waves in the Upper Mantle, $J$. Geophys. Res. 70, 4641-4651.

Ben-Menahem, A. and D. G. Harkrider (1964). Radiation patterns of seismie surface waves from buried dipolar point sources in a flat stratified Earth, J. Geophys. Res. 69, 2605-2620.

Brune, J. N. (1968). Seismic moment, seismicity, and rate of slip along major fault zones, $J$. Geophys. Res. 73, 777-784.

Brune, J. N. and C. R. Allen (1967). A low-stress-drop, low magnitude earthquake with surface faulting: the Imperial, California earthquake of March 4, 1966, Bull. Seism. Soc. Am. 57, $501-514$.

Brune, J. N. and C. Y. King (1967). Excitation of mantle Rayleigh waves of period 100 seconds as a function of magnitude, Bull. Seism. Soc. Am. 57, 1355-1365.

Byerly, P. (1926). The Montana earthquake of June 28, 1925, G.M.C.T., Bull. Seism. Soc. Am. 16, $209-265$.

Gilman, R. (1960). Report on some experimental long-period seismographs, Bull. Seismo. Soc. Am. $50,553-559$.

Gutenberg, B. (1956). Great earthquakes 1896-1903, Trans. Am. Geophys. U. 37, 608-614.

Gutenberg, B. and C. F. Richter (1954). Seismicity of the Earth and Associated Phenomena, New York, Hafner Publishing Co., 310 p.

Maruyama, T. (1963). On the force equivalents of dynamical elastic dislocations with reference to the earthquake mechanism, Bull. of Earthquake Res. Inst. 41, 467-486.

Richter, C. F. (1958). Elementary Seismology, San Francisco, W. H. Freeman and Co., 768 p.

Seismological Laboratory

California Institute of Technology

Pasadena, California

Division of Geological Scrences

Contribution No. 1559

Manuseript received September 16, 1968. 